\title{
Erratum to: The Experience of Racism and Anxiety Symptoms in an African-American Sample: Moderating Effects of Trait Mindfulness
}

\author{
Jessica R. Graham • Lindsey M. West • Lizabeth Roemer
}

Published online: 31 October 2012

(C) Springer Science+Business Media New York 2012

\section{Erratum to: Mindfulness}

\section{DOI 10.1007/s12671-012-0133-2}

In the original version of the article, there is an error in the interpretation of the significant interaction. The second paragraph on page 6 should read as below, and the correct image for Fig. 1 is also presented:

To interpret this interaction, we followed the procedures of Aiken and West (1991). Results indicated that the relationship between past year frequency of racist events and anxious arousal is marginally significantly positive at low levels of mindfulness $(\beta=0.324 t=1.90, p=0.06)$ and not significant at high levels of mindfulness $(\beta=-0.26, t=-1.38$, $p=0.17$ ) (see Fig.1).

The online version of the original article can be found at http://dx.doi.org/ 10.1007/s12671-012-0133-2.

\section{J. R. Graham $(\bowtie) \cdot$ L. Roemer}

Department of Psychology, University of Massachusetts Boston, 100 Morrissey Blvd.,

Boston, MA 02125, USA

e-mail: Jessica.Rose.Graham@gmail.com

\section{M. West}

Education Discovery Institute and Department of Psychiatry and Health Behavior, Georgia Health Sciences University,

Augusta, GA, USA

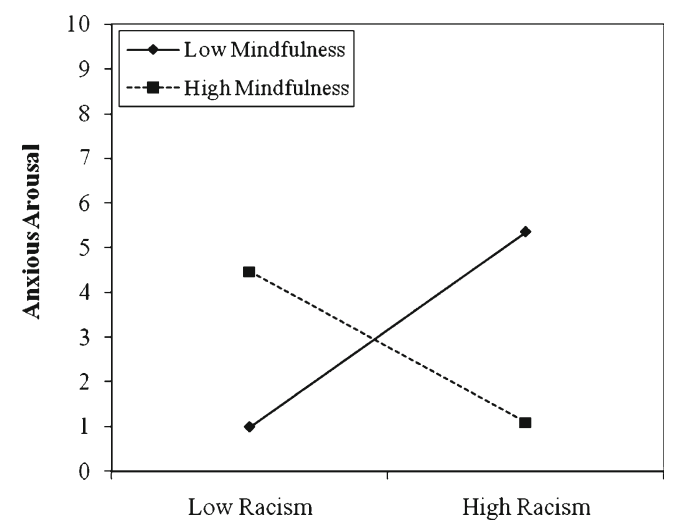

Fig. 1 Relationship between past-year frequency of racist events and anxious arousal 